\title{
Entre Caps AD e Comunidades Terapêuticas: o cuidado pela perspectiva dos usuários de um Caps AD
}

\author{
Between Caps AD and Therapeutic Communities: care from the \\ perspective of users of Caps $A D$
}

Ana Caroline de Moraes Oliveira Quintas ${ }^{\mathbf{1}}$, Priscilla dos Santos Peixoto Borelli Tavares ${ }^{\mathbf{1}}$

DOI: $10.1590 / 0103-11042020 E 317$

\begin{abstract}
RESUMO O debate em torno dos dispositivos e modelos de cuidado destinados aos usuários problemáticos de álcool e outras drogas tem ganhado cada vez mais espaço nas políticas públicas. A partir da discussão sobre os paradigmas da abstinência e da redução de danos, buscou-se investigar as relações e os sentidos que os usuários atribuem a esses paradigmas por meio da utilização das Comunidades Terapêuticas e dos Centros de Atenção Psicossocial Álcool e Drogas. Para isso, utilizou-se a metodologia da entrevista semiestruturada com usuários da rede de saúde mental que já haviam utilizado ou utilizavam os serviços supracitados. Além disso, investigaram-se os sentidos atribuídos ao conceito de redução de danos. Constatou-se que a utilização desses serviços possui pontos de convergência e divergência e que os momentos da busca por cada serviço não estão relacionados somente com uma demanda por tratamento. Observaram-se, também, a fragilidade na apreensão do conceito de redução de danos e a presença do ideal da abstinência na busca pelo tratamento. A partir da perspectiva dos usuários, espera-se contribuir para a ampliação das práticas de saúde mental no Sistema Único de Saúde.
\end{abstract}

PALAVRAS-CHAVE Redução do dano. Drogas ilícitas. Terapia.

\begin{abstract}
The debate regarding care models for problematic users of alcohol and other drugs has increased in Brazilian public policies. Based on the discussion on the abstinence and harm reduction paradigms, we sought to investigate the relationships and meanings that users attribute to such paradigms through the use of Therapeutic Communities and Psychosocial Care Centers for Alcohol and Drugs. For that, we used the semi-structured interview methodology with users of the mental health network who had already used the services mentioned above. In addition, the meanings attributed to the concept of harm reduction were investigated. It was found that the use of these services has points of convergence and divergence and that the moments of searching for each service are not related only to a demand for treatment. It was also observed a weak understanding of the concept of harm reduction and the presence of an abstinence ideal in the search for treatment. This research hopes to contribute to the expansion of mental health practices mainly, in the Brazilian Unified Health System.
\end{abstract}

KEYWORDS Harm reduction. Illicit drugs. Therapy. 


\section{Introdução}

Até o final século XX e início do século XXI, as políticas públicas brasileiras destinadas aos usuários de álcool e outras drogas estavam atreladas, principalmente, ao paradigma do proibicionismo, que coloca a questão do uso de drogas diretamente vinculada a um problema moral ou de ordem criminosa, de modo que as intervenções pensadas sob essa ótica visam a uma sociedade livre de drogas $\mathbf{1}$. Dessa forma, seja no âmbito da saúde ou da justiça, as políticas públicas dirigidas a esses usuários orientavam um tratamento pautado na abstinência, sendo este realizado por meio da institucionalização e do isolamento social.

As internações se sucediam em hospitais psiquiátricos ou em Comunidades Terapêuticas (CT), ambas as instituições, em sua maioria, privadas e que, no encaminhamento do tratamento, visavam, prioritariamente, o lucro ${ }^{2}$. Reforçando esse cenário, temos um momento histórico no qual a rede de saúde, até o final da década de 1980, estava destinada somente aos trabalhadores que contribuíam para a previdência social além de ausência de outros dispositivos voltados a esse público específico. Foi nesse cenário que as $\mathrm{CT}$ foram ganhando espaço, iniciando na década de 1970 e tendo uma maior expansão na década de 19901,3.

Paralelamente, na década de 1990, observamos, na esfera da saúde pública, a emergência de outras propostas para o cuidado destinado aos usuários problemáticos de álcool e outras drogas: o paradigma da redução de danos. No Brasil, estratégias de redução de danos começaram como consequência da preocupação com a disseminação do vírus HIV (Vírus da Imunodeficiência Humana) a partir do compartilhamento de seringas pelos usuários de drogas injetáveis e devido à consequente instauração do Programa de Troca de Seringas ${ }^{\mathbf{4}}$. Seguindo esse movimento, a partir da década de 2000 , o cenário das políticas públicas brasileiras em relação às drogas começou a sofrer mudanças; iniciaram-se propostas e projetos na esfera do Ministério da Saúde que tentaram retirar cada vez mais a questão do uso problemático da droga do âmbito da justiça, reafirmando a importância desta como um desafio para a saúde, principalmente, para o campo da saúde mental. Nesse momento, as políticas públicas de drogas começaram a reorientar o cuidado dos usuários problemáticos de álcool e outras drogas para o paradigma da redução de danos. Aqui, podemos ressaltar os Centros de Atenção Psicossocial Álcool e Drogas (Caps AD) como um dos dispositivos protagonistas nesse cuidado. Partindo da concepção de que não se pode alcançar o ideário de uma sociedade livre de drogas, o paradigma da redução de danos propõe estratégias para minimizar os riscos e os danos relacionados com o uso'. Logo, as estratégias de cuidado - que incluem, também, a família e a comunidade - vão-se delineando a partir das experiências e necessidades de cada usuário, de modo que a participação deste como um sujeito ativo em seu processo de tratamento torna-se algo fundamental para essa racionalidade ${ }^{\mathbf{1}, \mathbf{2}}$. Podemos citar a aprovação da Lei no 10.2016, de 6 de abril de 2001, que "dispõe sobre a proteção e os direitos das pessoas portadoras de transtornos mentais e redireciona o modelo assistencial em saúde mental"5, e a Política do Ministério da Saúde para Atenção Integral a Usuários de Álcool e outras Drogas ${ }^{6}$, elaborada por esse órgão em 2003, como marcos importantes que se orientam a partir da racionalidade da redução de danos e afirmam a importância do trabalho com programas de baixa exigência dentro de uma perspectiva de saúde pública, pois esta, por ser uma proposta mais flexível e não ter a abstinência total como única direção, consegue comtemplar uma parcela maior da população ${ }^{6}$.

Contudo, é importante não perder de vista o paradoxo e a luta de forças que acompanham o cenário da política sobre drogas brasileira. Ao mesmo tempo que se observa a aprovação, no âmbito da saúde, de políticas de redução de danos, não se extingue o discurso proibicionista. Como exemplo, temos que o Brasil continua sendo signatário de convenções internacionais que visam à repressão ao 
tráfico e uso de drogas e há, também, parcerias institucionais entre o Conselho Federal de Entorpecentes e as CT, já nos anos 1980/907. Segundo Boarini e Bolonheis-Ramos ${ }^{3}$, até o ano de 2010, as CT não tinham entrada na saúde, estando ligadas somente ao Sistema Único de Assistência Social. A entrada dessas instituições no Sistema Único de Saúde (SUS) se deu pela confluência de muitos atores: interesses políticos, empresariais e até mesmo da população, principalmente, quando as cenas de uso passaram a ocupar as cidades.

Consequentemente, foi promulgado o Decreto $n^{0} 7.179 / 10$, que "institui o Plano Integrado de Enfrentamento ao Crack e outras Drogas, cria o seu Comitê Gestor, e dá outras providências"8 e lança editais que preveem o apoio financeiro para as $\mathrm{CT}$ a partir dos recursos do SUS. Ao mesmo tempo, a Portaria $n^{\circ} 3.088 / 11$

Institui a Rede de Atenção Psicossocial para pessoas com sofrimento ou transtorno mental e com necessidades decorrentes do uso de crack, álcool e outras drogas, no âmbito do Sistema Único de Saúde?

Essa portaria coloca os Caps AD como protagonistas do cuidado - contínuo, de base territorial, intersetorial e promotor de vínculos - destinado aos usuários problemáticos de álcool e outras drogas. Observa-se mais um paradoxo da política de drogas, pois, apesar de ter como orientação o paradigma da redução de danos, esta insere as CT na Rede de Atenção Psicossocial (Raps) como Serviços de Atenção em Regime Residencial.

Com o aumento do conservadorismo no País, em 2019, tem-se a validação do Decreto $n^{\circ} 9.761 / 19$ que aprova a Política Nacional sobre Drogas ${ }^{10}$. Acerca desse decreto, é importante ressaltar alguns pontos. O primeiro está relacionado com o fato de o texto ressaltar que o uso indevido de substâncias é um problema de saúde pública, ao mesmo tempo que os Ministérios responsáveis pela implementação e articulação da política são o Ministério da Cidadania e o Ministério da Justiça e Segurança Pública. Isso demonstra um retorno da questão relativa ao tratamento cada vez mais para o âmbito da justiça. Outro ponto de suma importância está relacionado com o redirecionamento da política, que tem como objetivo uma sociedade protegida do uso e da dependência das drogas lícitas e ilícitas, com isso, a finalidade do tratamento para os usuários problemáticos de álcool e outras drogas passa a ser a obtenção da abstinência. Dessa forma, inclui-se, com destaque, a participação das CT para a constituição dessa nova política, as quais, no decorrer do texto, por vezes, ganham o status de unidades de tratamento e acolhimento e, por vezes, são descritas com o caráter de unidades residenciais transitórias. Além disso, o decreto, que vem descrevendo a importância das parcerias público-privadas, reforça que a política nacional sobre drogas deve estimular e apoiar, inclusive financeiramente, tanto o trabalho quanto a estruturação física das $\mathrm{CT}^{10}$. Alinhadas a esse projeto, têm-se mudanças na Política Nacional de Saúde Mental, na qual a estratégia de redução de riscos sociais e à saúde e danos aparece como via para que o paciente logre a abstinência"1.

Diante disso, observa-se que a discussão em torno dos cuidados que devem ser destinados aos usuários de drogas tem-se dado, no Brasil, principalmente, em torno desses dois paradigmas: o da abstinência e o da redução de dano, diretamente relacionados com as CT e os Caps $\mathrm{AD}$ respectivamente. No entanto, constata-se, na prática do trabalho em saúde mental, que muitos usuários do SUS, por vezes, utilizam-se dos dois serviços até mesmo de forma concomitante. Entendendo a importância destes na gestão do seu cuidado, tem-se como questão central neste artigo a relação dos usuários problemáticos de álcool e outras drogas com os paradigmas investigados. Assim, este trabalho tem por objetivo investigar o que os usuários da Raps de uma determinada área do Rio de Janeiro entendem por redução de danos e as funções que eles atribuem aos dispositivos Caps AD e às CT. Desse modo, espera-se buscar 
elementos que contribuam para o cuidado e para as práticas em saúde mental.

\section{Metodologia}

Para a realização desta pesquisa, utilizou-se a metodologia qualitativa entendo que esta possibilita coletar dados sobre os processos de interação cotidiana e histórica, bem como o entendimento do indivíduo no seu contexto ${ }^{12,13}$. Para a coleta dos dados, realizaram-se a revisão bibliográfica não sistemática na literatura concernente ao tema e a técnica da entrevista semiestruturada. Segundo Lima ${ }^{12}$, a entrevista é um dos recursos habitualmente utilizados pelos pesquisadores das ciências sociais, de modo que, por meio dessa técnica, é possível captar histórias, experiências, lembranças e valores dos entrevistados. Para a realização das entrevistas, foi utilizado um roteiro com questões sobre o tema pesquisado, a partir de perguntas fechadas e abertas. A escolha dessa técnica se deu, pois esse modelo possibilita que, a partir da fluidez da entrevista, tanto o entrevistador possa colocar novas questões quanto o entrevistado tenha liberdade de falar.

As entrevistas foram realizadas no período de outubro a dezembro de 2019 em um Caps AD localizado no município do Rio de Janeiro (RJ). Para poder pensar as funções que os usuários atribuem aos Caps $\mathrm{AD}$ e às $\mathrm{CT}$, compreender o que esses serviços produzem de efeito na vida dos usuários e compreender o que os usuários dos serviços de saúde entendem por redução de danos, entrevistamos usuários do referido Caps $\mathrm{AD}$ que, em tratamento no ano de 2019, já tenham ou ainda fazem uso de CT, sendo estas financiadas ou não pelo poder público.

No total, foram realizadas nove entrevistas, sendo todas elas com usuários que se identificaram como sendo do gênero masculino. Os entrevistados foram convidados a assinar o Termo de Consentimento Livre e Esclarecido, e todos autorizaram a gravação das entrevistas.
Posteriormente, as gravações foram transcritas. Feito isso, a técnica da análise de conteúdo proposta por Campos ${ }^{\mathbf{1 4}}$ foi utilizada, uma vez que ela possibilita articulação dos sentidos das falas a pressupostos teóricos, sempre considerando processos sociais e históricos nos quais aquele material foi produzido. Nesta análise, observaram-se algumas etapas que consistem em: leituras flutuantes do material; seleção das unidades de análise; e processo de categorização/subcategorização ${ }^{\mathbf{1 4}}$. As falas dos entrevistados foram identificadas pela letra $\mathrm{E}$, seguida pelo número correspondente.

$\mathrm{O}$ projeto seguiu as determinações da Resolução n ${ }^{\circ}$ 580/2018 do Conselho Nacional de Saúde ${ }^{15}$. Além disso, esta pesquisa foi submetida ao Comitê de Ética em Pesquisa da Secretaria Municipal de Saúde do Rio de Janeiro (CEP-SMSRJ), com número de aprovação 18337819.4.0000.5279. Não houve qualquer tipo de suporte financeiro para a pesquisa.

\section{Resultados e discussão}

\section{Alguns apontamentos sobre os usos do Caps AD e Comunidades Terapêuticas}

Historicamente, as CT foram instituições consolidadas por Maxwell Jones, por volta dos anos 1950/60. Estas tinham como direção a reformulação dos hospitais psiquiátricos por meio da horizontalização dos papéis dos profissionais e dos internos, com intensa participação destes nas decisões institucionais e sobre seu tratamento ${ }^{16}$. Segundo Santos ${ }^{17}$, uma das poucas características que as $\mathrm{CT}$ contemporâneas têm com as de Maxwell Jones é a convivência entre pares, uma vez que, nelas, tanto as hierarquias como os planos terapêuticos são bem definidas. Dessa forma, é importante entendermos um pouco da rotina das CT às quais nos referimos neste trabalho a partir das falas dos entrevistados. 
[...] Acorda de manhã, toma o café da manhã. Um pão com café sem açúcar e o pão sem nada. À tarde, o almoço, arroz, feijão, angu, pé de galinha. Na hora do lanche, um pão sem a manteiga, sem nada, com um café sem açúcar. A Janta, arroz, feijão, pé de galinha com angu. Quando não é pé de galinha é pescoço, quando tem arroz na janta. Segunda, quarta e sexta são dias de jejum, você só pode comer depois das 3 horas da tarde. Comer e beber água. Claro que eu não segui isso à risca né, eu vou escovar o dente eu vou beber água. $E$ assim, vinha. Sábado era o lazer. (E05).

É, as tarefas né. A gente acordava. Tinha laborterapia, tinha o café da manhã. Laborterapia. Uma devocional primeiro, aí seguido de devocional o café da manhã, uma laborterapia. Depois seguia o almoço depois do almoço tinha uma reunião. Depois dessa reunião tinha um tempo livre pra atividade esportiva. Lazer, esporte. E 5 h30 tinha uma outra reunião e 7 horas da noite a janta. (E09).

Era essa questão de religião, de falar muito de Deus, Deus, ler bíblia toda hora. Ajoelhar, ter que fazer jejum, ter que ir pro monte orar, acordar meia noite, ir pro monte orar. Não acho isso certo. Eu acho que a pessoa tem que ter o livre arbítrio de poder se tratar [...]. (E01).

Essas falas corroboram a pesquisa realizada no ano de 2017 pelo Instituto de Pesquisa Econômica Aplicada (Ipea) sobre o perfil das CT no Brasil. Nessa pesquisa, foram ressaltados alguns pontos de convergência que direcionam as práticas nessas instituições, os quais podemos destacar: a condução de um tratamento a partir do isolamento social e da consequente convivência entre pares; a instalação desses dispositivos em áreas rurais; a espiritualidade como meio de conversão moral; a laborterapia entendida como terapêutica; e a disciplina ${ }^{7}$. Nessa mesma direção, Aguiar ${ }^{18}$ aponta "disciplina, fé e trabalho"18(38) como pilares fundamentais que caracterizam as $\mathrm{CT}$ atualmente no Brasil. Dessa forma, podem-se destacar, nessas instituições, características do que Goffman ${ }^{19}$ nomeia de instituições totais: uma tendência ao fechamento da instituição e ao isolamento dos usuários do mundo externo; um processo nomeado de 'mortificação do eu', processo no qual o interno é despojado de seu papel civil, despojado de seus bens e enquadrado em uma série de regras que promovem uma homogeneidade dos internados e os privam de liberdade e autonomia. Natalino ${ }^{20} \mathrm{e}$ Damas $^{2} 1$, em suas análises, corroboram a ideia de que as CT, resguardadas algumas características, podem ser consideradas tipos de instituições totais. Para Damas $^{21}$, um dos objetivos centrais das CT seria a reinserção social, após a realização de um processo de mudança subjetiva do indivíduo que, consequentemente, geraria uma mudança no seu papel na sociedade. No entanto, os autores concordam que, no processo de mortificação do eu, há a produção de uma subjetividade enquadrada na lógica institucional que, por vezes, amplia a própria dependência da instituição. Como consequência, percebe-se que

\section{A disjunção entre os repertórios de ser-na- -instituição e ser-fora-da-instituição pode se manifestar como inadaptação à vida civil e, em última instância, reincidência20(56).}

Reincidência esta que observamos nas falas dos entrevistados quando lhes perguntamos sobre a quantidade de vezes que já estiverem em CT:

Ah, umas dez vezes. Mas nenhuma deu certo. (E01).

Umas quatro, cinco vezes mais ou menos. (EO4).

Ah eu fui duas vezes. Uma eu fiquei três anos e seis meses. (E08).

No Brasil, as CT voltadas exclusivamente para usuários problemáticos de álcool e outras drogas foram influências tanto pelo Modelo Minessota quanto pelo modelo Synanon 18,21. Partindo dessas influências, identifica-se que, atualmente, as CT configuram-se por diferentes abordagens 
[...] em algumas prevalece o modelo religioso-espiritual, noutras a base é a atividade laboral, e ainda outras prevalece o modelo médico, assistencialista, ou com abordagem predominantemente psicológica, podendo haver uma mistura de abordagens ${ }^{21(53)}$.

Em nossa pesquisa, apesar da predominância da abordagem religiosa, observamos que, em alguns casos, essa abordagem mistura-se com outras de cunho assistencialista e/ou psicológico.

[...] Aí cada um tem o seu atendimento. Tem a psicóloga, médica, a professora. Se você não tem estudo né, tem uma professora lá que se doa pra ensinar, se você não sabe ler nem escrever. É legal. Tu sai empregado, eles têm o seu documento. (E06).

Tem psicólogo. (E09).

Apesar da presença desses profissionais em determinadas $\mathrm{CT}$, chama atenção que nem a Resolução de Diretoria Colegiada (RDC) da Agência Nacional de Vigilância Sanitária (Anvisa) no 29/201122 - que regulamenta condições sanitárias mínimas para o funcionamento das CT - nem a Resolução ${ }^{0} 1 / 2015$ do Conselho Nacional de Políticas sobre Drogas (Conad) ${ }^{\mathbf{2 3}}$ - que regulamenta, no âmbito no Sistema Nacional de Políticas Públicas sobre Drogas (Sisnad), as CT - estabelecem a necessidade de uma equipe mínima de profissionais de saúde nessas instituições ${ }^{18,24}$. Diante disso, os usuários trazem a presença de uma equipe qualificada como uma das características importantes do Caps AD.

Ah, o Caps é diferente, cara. O Caps tem estrutura né. Tem o médico, como eu falei pra você, tem assistente social. Nesses lugares não tem nada disso. É pastor, oração, igreja, jejum, comida totalmente horrivel. (E01).

Aqui não, lá é uma coisa. Aqui eu senti é o centro de recuperação é M., é da prefeitura, aqui você tem médico, toma remédio, medicação. Esses lugares não têm médico, não tem medicação, não tem nada, esses lugares é tudo assim uma terapia na tua mente. É tudo na mente, é oração e o cara não toma remédio não toma nada. É fazer as tarefas e ficar ali preso, um ano, dois anos. Isso não existe. Existe sim lá pra quem quer. Ficar um ano lá dentro. 'Pow não vou aguentar ficar preso aqui não, deus me livre, vou pirar, vou ficar maluco' [...]. (E03).

Os Caps são dispositivos da Raps que têm como função organizar a demanda da rede de saúde mental, tendo como objetivo o acompanhamento longitudinal e a reinserção social. Esses dispositivos, em consonâncias com os princípios da reforma psiquiátrica e as diretrizes do SUS 5 , possuem equipes multidisciplinares que trabalham com a lógica do cuidado de base territorial e comunitária. Desse modo, levam em conta a complexidade da vida e das relações de cada usuário a fim de ofertarem atenção integral por meio das atividades oferecidas no próprio serviço, como também da articulação intersetorial, articulação com o território, comunidade, além de serviços de arte, cultura, lazer e geração de renda ${ }^{\mathbf{2 5 , 2 6}}$. A presença de uma equipe multidisciplinar nesses dispositivos está diretamente relacionada com a reforma psiquiátrica que, na tentativa de produzir uma atenção psicossocial, começou a incluir outros saberes e práticas para além do saber biomédico, de modo que o sofrimento passou a ser concebido a partir de outra lógica. Isso significa dizer que a atenção psicossocial reconhece que o contexto social no qual estão inseridos os diferentes sujeitos também influencia na sua constituição e no seu sofrimento psíquico ${ }^{14}$. Diante disso, sobre sua rotina no Caps, os entrevistados relatam o seguinte:

Olha, eu venho pra cá segunda, quarta e sexta. Faço as terapias que tem, redução de danos, caminhada com o terapeuta J., tem o futebol também. Tem esse grupo de redução de danos. Venho pra cá, fico o dia aqui tem as terapias, tem o samba que 
rola aí. E é isso, cara. É um local que você procura uma ajuda pra poder fugir da rotina do uso. Por exemplo, se eu não tivesse no Caps eu ia estar fazendo o uso, então o Caps ajuda bastante nesse tipo de questão. (E01).

Ah, agora eu venho uma vez por semana. Mas o seu J, algum tempo atrás, quando eu tava na rua, tava pedindo pra mim vim duas vezes por semana, entendeu? Eu vinha duas vezes por semana pegar a medicação. (E04).

Sim, se seu tiver... Por exemplo, hoje está no meu PTS eu tá aqui. Hoje eu tomo café da manhã, almoço, café da tarde e janto. E faço parte da oficina de luminária e redução de danos. (E05).

Hoje em dia eu venho mais pra cá pra fazer outras coisa né? Conversar, café com não sei o quê. (E08).

Pode-se observar que, diferentemente do relatado sobre as $\mathrm{CT}$, no Caps $\mathrm{AD}$, os entrevistados possuem diferentes rotinas. Isso se deve ao que o usuário E04 chama de PTS, Projeto Terapêutico Singular, que é uma estratégia de cuidado amplamente utilizada nos serviços de saúde mental que reforça a importância de um trabalho multidisciplinar, pois, por meio da discussão em equipe, é construído um projeto terapêutico que entenda as necessidades do sujeito integralmente. Isso significa que esse projeto é construído de forma articulada não só com o Caps, mas também com a comunidade, família e toda rede intersetorial, tendo como objetivo, entre outros, a autonomia e a construção de vínculos de cada usuário. Desse modo, o usuário tem um papel de protagonismo na construção desse PTS que deve ser reavaliado e reconstruído permanentemente ${ }^{25}$.

Nas falas abaixo, observam-se os diferentes motivos pelos quais os entrevistados procuram o Caps AD. Algumas dessas falas corroboram a pesquisa de Machado, Modena e $\mathrm{Luz}^{27}$, que fala sobre as diferentes necessidades trazidas pelos usuários do Caps $\mathrm{AD}$ quando estes buscam esse serviço. São estas: cuidado para sofrimento psíquico e orgânico, reconstrução dos laços sociais e acesso a serviços básicos como alimentação e higiene pessoal.

Quando eu me sinto depressivo, entendeu? Hoje, por exemplo, eu acordei de manhã aí olhei pro relógio ainda eram 7 e pouca, e aqui só pode entrar as 8. Quer saber, eu vou andando devargazinho e vou chegar lá. Aí eu vim [...]. (E05).

No momento de desespero, no momento de que você vê que não tá dando mais, entendeu? Que você precisa de uma ajuda. Que chega um momento que você usa tanta droga, tanta droga que nem você mais aguenta usar. Nem a droga faz mais efeito, entendeu? Principalmente, o crack. (E01).

Pra conversar, conversar com alguém. Pra ficar perto de pessoas. (EO8).

Quando falam sobre os momentos nos quais procuram as CT, pode-se perceber que, assim como em relação aos Caps AD, os entrevistados não buscam somente tratamento. Desse modo, eles relatam também a procura por abrigo ou mesmo uma busca espiritual.

Eu escolhia porque eu não tinha pra onde ir né, cara. Eu tava na rua. Eu achava que eu poderia ali, poderia abrir uma porta pra mim, ia ser o caminho. Mas, geralmente, eram lugares evangélicos, onde você teria que ter uma doutrina evangélica [...]. (E01).

Porque lá eu sempre tive uma chama de Deus na minha vida, eu sempre fui enrolado com Deus desde os meus 17 anos. Emaioria das Comunidades Terapêuticas são cristã, então ajuda você a se libertar, ajuda muito. Eas vezes, prejudica muito. (E02).

Quando eu tô na pior, quando eu tô na pior sem ter pra onde ir, como eu tô agora, entendeu? Depois de ter feito muita bobagem é que eu paro, reflito, realmente, tem que ser num centro de recuperação. Tentei ficar numa quitinete sozinho lá em Nilópolis só consegui ficar um mês, mas fiz muita bobagem. Cheirava lá, entendeu? Cheguei a levar prostituta lá pra dentro. (E04). 
Talvez por tá na rua, prefira até tá lá dentro, porque eu não gosto de ficar internado não. (E06).

Diante dos diferentes motivos relatados em relação aos momentos nos quais os entrevistados buscam cada instituição, destaca-se um ponto de convergência: que é quando os entrevistados referem estar em uso intensivo. No entanto, sendo o Caps AD um serviço aberto e que propõe um cuidado longitudinal, alguns entrevistados relatam procurar esse dispositivo também para a continuidade do tratamento. Além disso, alguns entrevistados referem utilizar esses dispositivos de forma conjunta.

Eu conciliava as duas coisas. Procurava o Caps e procurava um lugar pra mim sair, se isolar do mundo. Um lugar onde realmente ia me libertar. (EO2).

Assim, ficando lá no centro terapêutico, no centro de recuperação é bom pra mim, muito bom. E vir aqui no Caps também é bom pra pegar remédio, pra passar pela minha referência, pra continuar conversando com ela, entendeu? Porque me aconselha, guia em algumas coisas, fala aquilo que eu preciso ouvir. (E04).

Assim como em nossa pesquisa, Natalino identifica que as pessoas que usam drogas procuram variados tipos de tratamento durante sua vida. À vista disso, percebe-se que, diante de algumas pistas, não é possível identificar com precisão os motivos que fazem cada pessoa, a cada momento e a cada escolha, procurar cada instituição. Dessa forma, observamos que, por vezes, os mesmos usuários recorreram a internações e aos Caps AD concomitantemente. Para Natalino:

Nesse percurso, recorrem às mais diversas modalidades de atenção, sejam elas pautadas ou não pela internação, abstinência e/ou lógica da RD. Sua escolha tende a ser quase sempre condicionada pela efetiva disponibilidade dos serviços no momento da busca e por sua percepção, em cada circunstância, sobre que serviço pode melhor atender às suas demandas imediatas 20(31).

\section{Algumas compreensões sobre a redução de danos}

Um dos objetivos desta pesquisa está relacionado com os sentidos apreendidos em torno do conceito de redução de danos. Dos nove usuários entrevistados, somente um ainda não havia participado do grupo de redução de danos oferecido pelo Caps AD no qual a entrevista foi realizada. Diante desse dado, chama atenção o fato de os entrevistados relacionarem a redução de danos somente como uma técnica de redução na quantidade do uso.

Ah, redução de danos. Sabe o quê que acontece? Eu vi ali, do meu ver, do meu ver. Vou te falar, as pessoas 'Ah, não usa cinco não, usa um'. Isso é redução de danos, eu não quero usar um, que eu não consigo usar um. Vou ser sincero contigo que eu era compulsivo. Aí 'Você tá usando quantos pó?' 'dez' 'Usa cinco, diminui, aí vai diminuindo' Mas tem que parar, não é usar dois. Se eu usar dois eu vou usar uma carga toda. (E03).

Redução de danos é você reduzir o uso, né cara. Tentar reduzir o uso aos poucos até parar, entendeu? (E01).

É o que eu entendo como redução e danos é que é um trabalho em cima de diminuir o uso da dependência química. (E09).

É possível identificar em algumas falas estratégias criadas pelos entrevistados para conciliar o uso de substâncias com o trabalho e outros afazeres da vida. No entanto, esses entrevistados não as identificam como estratégias de redução de danos, uma vez que relacionam esse conceito com a perspectiva supracitada.

Perante Deus não uso cocaína, mas ainda tô tomando uma cachacinha, entendeu? Tipo assim, 
*Orcid (Open Researcher and Contributor ID). ainda preciso de ajuda, eu não tô totalmente curado. Porque eu não uso droga, droga eu uso, cachaça é droga, a pior droga que tem. Mas eu não fico doidão, não fico fazendo besteira, entendeu? Eu tomo assim, um pouquinho agora pra fazer o almoço, quem faz o almoço sou eu. Cuido dela, quem lava a louça sou eu, quem compra roupa pra ela [...] Mas aí eu tenho um limite. Vou tomar um negocinho, mas eu tenho que trabalhar amanhã de manhã, eu paro aí vou descansar. Trabalhar pra não dar mole. (EO3).

Petuco ${ }^{\mathbf{2 8}}$ organiza a história da redução de danos em três momentos. A partir dessa história, ele mostra como a redução de danos na Inglaterra e na Holanda nasceu a partir de técnicas como a "Terapia da Substituição"28(134) e da distribuição/troca de seringas. No Brasil, a estratégia de redução de danos, que se iniciou também como um programa de troca de seringas, vai ganhando outros sentidos e formas. Desse modo, aproxima-se cada vez mais da clínica ampliada, amplifica suas práticas e inventa uma nova ética de cuidado. Corroborando essa ideia, Souza ${ }^{2}$ entende a redução de danos para além do campo das técnicas. Para o autor, ela está atrelada a uma dimensão de cuidado que leva em conta a experiência singular de cada sujeito. Ou seja, ao contrário do paradigma da abstinência, que produz um saber hegemônico sobre a relação que se deve ter com o uso de drogas, a redução de danos abre as portas para que os usuários possam falar das suas experiências.

[...] Foi o que a I. falou pra mim, me perguntou '05, como é que você reduz seus danos?'. Vindo no Caps, que aqui eu não uso nada, entendeu? Eu fora daqui, eu sou uma bomba relógio. (E05).

Diante da polarização em que se instaura o campo das drogas, na qual as possibilidades possíveis só se dão quando a favor ou contra seu uso, é importante ressaltar que, assim como E04 nos sinaliza, a redução de danos não se opõe à abstinência como uma possibilidade, mas com o único objetivo possível, produzindo então uma terceira via diante dessa polarização ${ }^{2}$.

A redução de danos que segundo a pessoa que explicava é realmente pra pessoa diminuir o uso de drogas ou então chegar ao ponto até de parar. Porque o Caps trabal ha com a questão do seguinte: a pessoa pode até usar droga, segundo o que eu entendo, mas controlável, se controlando. Se conseguir parar, 100\% parar mesmo, parabéns. Mas se não pelo menos controlar o uso de drogas, sem ficar fora de si, sem ficar doidão, sem fazer bobagem, sem ficar fora de si, sem ficar, entendeu? (E04).

Pensar a abstinência como única meta é pensar em um tratamento no qual a droga é o foco, é pensar a substância e suas estruturas químicas como o mal em si, excluindo a relação e o sentido da experiência do drogar-se. Se a droga é o único problema, infere-se que, com o objetivo de ver-se livre dela, as pessoas deveriam deixar de frequentar certos lugares, deixar de encontrar certar pessoas e evitar certos comportamentos. Seguindo por este caminho, o das privações, o que se tem é um empobrecimento das relações subjetivas. Ao contrário, a partir do paradigma da redução de danos, tira-se o foco do tratamento da droga. Tirar o foco da droga é entender que só podemos analisar os efeitos da substância quando na relação com a subjetividade de cada usuário e, consequentemente, seu território existencial ${ }^{29}$.

\section{Considerações finais}

A disputa entre os modelos de atenção aos usuários problemáticos de álcool e outras drogas tem ganhado cada vez mais o cenário das políticas públicas no Brasil, a saber: o modelo orientado pela concepção de liberdade, cuidado no território, na perspectiva de redução de danos, considerando os usuários enquanto sujeitos de direito, realizado nos Caps AD; e o modelo orientado pela segregação dos usuários e a abstinência enquanto única 
possibilidade, em que o foco é a droga e, em sua maioria, orientado pela perspectiva religiosa, realizado pelas CT. Santos ${ }^{24}$ considera que essas disputas

estão diretamente associadas aos diferentes sentidos - morais, simbólicos e políticos - atribuídos pelos diversos grupos sociais a essas substâncias e ao seu uso24(18).

Diante disso, este estudo oferece algumas pistas das relações que os usuários problemáticos de álcool e outras drogas estabelecem com os paradigmas da abstinência e da redução de danos, por meio dos usos e sentidos que estes atribuem às CT e aos Caps AD. Observamos, também, a presença de falas que sustentam a relação com as drogas baseadas no paradigma da abstinência.

Diante do debate aqui colocado e da inserção cada vez maior das CT nas legislações brasileiras, sublinha-se a relevância desta pesquisa no sentido de poder incluir as experiências trazidas pelos usuários do SUS. Posto isso, é necessário enfatizar a necessidade de mais pesquisas relativas ao tema, principalmente, àquelas atreladas ao campo das políticas públicas de saúde e, principalmente, aos princípios da reforma psiquiátrica garantidos pela Lei ${ }^{\circ}$ 10.216/015. Faz-se, também, imprescindível a regularidade de fiscalização dessas instituições pelos diversos órgãos responsáveis do Estado.

\section{Colaboradoras}

Quintas ACMO (0000-0002-2464-3786)* contribuiu para a concepção, o planejamento, a realização da pesquisa, análise dos dados, a redação e a aprovação final do manuscrito. Tavares PSPB (0000-0001-6503-3944)* contribuiu para a concepção, o planejamento, a redação, revisão crítica do conteúdo e a aprovação final do manuscrito.

\section{Referências}

1. Alves VS. Modelos de atenção à saúde de usuários de álcool e outras drogas: discursos políticos, saberes e práticas. Cad. Saúde Pública. 2009; 25(11):2309-2319.

2. Souza TP. A norma da abstinência e o dispositivo "drogas": Direitos universais em territórios marginais de produção de saúde (perspectivas da redução de danos) [tese]. Campinas: Universidade Estadual de Campinas; 2013. 335 p.

3. Bolonheis-Ramos RCM, Boarini ML. Comunidades terapêuticas: "novas" perspectivas e propostas higienistas. Hist. cienc. saude - Manguinhos. Rio de Janeiro. 2015; 22(4):1231-1248.

4. Andrade TM. Reflexões sobre Políticas de Drogas no Brasil. Ciênc. Saúde Colet. 2011; 16(12):4665-4674.

5. Brasil. Lei n ${ }^{0} 10.2016$ de 6 de abril de 2001. Dispõe sobre a proteção e os direitos das pessoas portadoras de transtornos mentais e redireciona o modelo assistencial em saúde mental. Diário Oficial da União. 9 Abr 
2001. [acesso em 2020 set 7]. Disponível em: http:// www.planalto.gov.br/ccivil_03/LEIS/LEIS_2001/ L10216.htm.

6. Brasil. Ministério da Saúde, Secretaria Executiva; Secretaria de Atenção à Saúde, Coordenação Nacional DST/AIDS. A política do Ministério da Saúde para a atenção integral a usuários de álcool e outras drogas. Brasília, DF: Ministério da Saúde; 2003.

7. Instituto de Pesquisa Econômica Aplicada. Nota Técnica $^{\circ}$ 21: Perfil das Comunidades Terapêuticas brasileiras. [internet]. 2017. [acesso em 28 jan 2020]. Disponível em: https://www.ipea.gov.br/portal/images/ stories/PDFs/nota_tecnica/20170418_nt21.pdf.

8. Brasil. Decreto $\mathrm{n}^{\circ} 7.179$, de 20 de maio de 2010. Institui o Plano Integrado de Enfrentamento ao Crack e outras Drogas, cria o seu Comitê Gestor, e dá outras providências. Diário Oficial de União. 21 Maio 2010. [acesso em 2020 set 7]. Disponível em: http://www. planalto.gov.br/ccivil_03/_Ato2007-2010/2010/Decreto/D7179.htm.

9. Brasil. Ministério da Saúde. Portaria no 3.088 , de 23 de dezembro de 2011. Institui a Rede de Atenção Psicossocial para pessoas com sofrimento ou transtorno mental e com necessidades decorrentes do uso de crack, álcool e outras drogas, no âmbito do Sistema Único de Saúde (SUS). Diário Oficial da União. 21 Maio 2013. [acesso em 2020 set 7]. Disponível em: http://bvsms.saude.gov.br/bvs/saudelegis/gm/2011/ prt3088_23_12_2011_rep.html.

10. Brasil. Decreto $\mathrm{n}^{\circ}$ 9.761, de 11 de abril de 2019. Aprova a Política Nacional sobre Drogas. Diário Oficial da União. 11 Abr 2019. [acesso em 2020 set 7]. Disponível em: http://www. planalto.gov.br/ccivil_03/_ato2019-2022/2019/ decreto/D9761.htm\#: :text=Promover\%20a\%20 estrat\%C3\%A9gia\%20de\%20busca,das\%20drogas\%201\%C3\%ADcitas\%20e\%20il\%C3\%ADcitas.

11. Brasil. Ministério da Saúde. Nota Técnica $n^{\circ}$ 11/2019-CGMAD/DAPES/SAS/MS. Esclarecimentos sobre as mudanças na Política Nacional de Saúde Mental e nas Diretrizes da Política Nacional so- bre Drogas. Diário Oficial da União. 4 Fev 2019. Disponível em: http://pbpd.org.br/wp-content/ uploads/2019/02/0656ad6e.pdf.

12. Lima M. O uso da entrevista na pesquisa empírica. In: Métodos de pesquisa em Ciências Sociais: Bloco Qualitativo. São Paulo: SESC- CEBRAP; 2016. p. 2441.

13. Alves ZMMB, Silva MHGFD. Análise qualitativa de dados de entrevista: uma proposta. Paidéia. Rib. Preto. 1992; (2):61-69.

14. Campos CJG. Método de análise de conteúdo: ferramenta para a análise de dados qualitativos no campo da saúde. Rev. Bras. Enferm. 2004; 57(5):611-614.

15. Conselho Nacional de Saúde. Resolução n ${ }^{\circ} 580$, de 22 de março de 2018. Regulamentar o disposto no item XIII.4 da Resolução CNS no 466, de 12 de dezembro de 2012, que estabelece que as especificidades éticas das pesquisas de interesse estratégico para o Sistema Único de Saúde (SUS) serão contempladas em Resolução específica, e dá outras providências. Diário Oficial da União. 16 Jul 2018. [acesso em 2020 set 7]. Disponível em: https://conselho.saude.gov.br/ resolucoes/2018/Reso580.pdf.

16. Brandão B, Carvalho J. Comunidade Terapêutica democrática ou nova racionalização de operação do poder psiquiátrico: referências históricas de sua emergência. Revista Ingesta. 2019; 1(1):268-282.

17. Santos MPG. Introdução. In: Santos MPG, organizadora. Comunidades Terapêuticas: temas para reflexão. Rio de Janeiro: IPEA; 2018. p. 9-16.

18. Aguiar ALV. Usuários de crack, instituições e modos de subjetivação: estudo das práticas e da eficácia terapêutica em uma comunidade terapêutica religiosa (RN). [dissertação]. Natal: Universidade Federal do Rio Grande do Norte, 2014.

19. Goffman E. Manicômios, prisões e conventos. São Paulo: Perspectiva; 1974.

20. Natalino MAC. Isolamento, disciplina e destino social 
em Comunidades Terapêuticas. In: Santos MPG, organizadora. Comunidades Terapêuticas: temas para reflexão. Rio de Janeiro: IPEA; 2018. p. 37-59.

21. Damas FB. Comunidades Terapêuticas no Brasil: expansão, institucionalização e relevância social. Rev. Saúde Públ. Santa Cat. [internet] 2013 [acesso em 2020 jan 20]; 6(1):50-65. Disponível em: http://revista.saude.sc.gov.br/index.php/inicio/article/view/173.

22. Agência Nacional de Vigilância Sanitária. Resolução - RDC no 29, de 30 de junho de 2011. Dispõe sobre os requisitos de segurança sanitária para o funcionamento de instituições que prestem serviços de atenção a pessoas com transtornos decorrentes do uso, abuso ou dependência de substâncias psicoativas. Diário Oficial da União. 1 Jul 2011. [acesso em 2020 set 7]. Disponível em: https://www20.anvisa. gov.br/segurancadopaciente/index.php/legislacao/ item/rdc-29-de-30-de-junho-de-2011.

23. Conselho Nacional de Políticas Sobre Drogas (Brasil). Resolução $n^{\circ}$ 1, DE 19 de agosto de 2015. Regulamenta, no âmbito do Sistema Nacional de Políticas Públicas sobre Drogas -Sisnad, as entidades que realizam o acolhimento de pessoas, em caráter voluntário, com problemas associados ao uso nocivo ou dependência de substância psicoativa, caracterizadas como comunidades terapêuticas. Diário Oficial da União. 28 Ago 2015. [acesso em 2020 set 7]. Disponível em: https:// www.in.gov.br/materia/-/asset_publisher/Kujrw0TZC2Mb/content/id/32425953/dol-2015-08-28-resolucao-n-1-de-19-de-agosto-de-2015-32425806.

24. Santos MPG. Comunidades Terapêuticas e a disputa sobre modelos de atenção a usuários de drogas no Brasil. In: Santos MPG, organizadora. Comunidades Terapêuticas: temas para reflexão. Rio de Janeiro: IPEA; 2018. p. 17-36.
25. Boccardo ACS, Zane FC, Rodrigues S, et al. O projeto terapêutico singular como estratégia de organização do cuidado nos serviços de saúde mental. Rev. Ter. Ocup. Univ. São Paulo. 2011; 22(1);85-92.

26. Brasil. Ministério da Saúde. Portaria no 336, de 19 de fevereiro de 2002. Dispõe sobre os Centros de Atenção Psicossocial - CAPS, para atendimento público em saúde mental, isto é, pacientes com transtornos mentais severos e persistentes em sua área territorial, em regime de tratamento intensivo, semi-intensivo e não-intensivo. Diário Oficial da União. 22 Fev 2002. [acesso em 2020 set 7]. Disponível em: https://bvsms.saude.gov.br/bvs/saudelegis/gm/2002/ prt0336_19_02_2002.html.

27. Machado AR, Modena CM, Luz ZMP. O que pessoas que usam drogas buscam em serviços de saúde? Compreensões para além da abstinência. Interface [internet]. 2020. [acesso 2020 jan 2]; 24:1-15. Disponível em: http://www.scielo.br/pdf/icse/v24/1807-5762-icse-24-e190090.pdf

28. Petuco DRDS. Redução de Danos: das técnicas à ética do cuidado. In: Ramminger T, Silva M, organizadores. Mais substâncias para o trabalho em saúde com usuários de drogas. Porto Alegre: Rede UNIDA; 2014. p. 133-148.

29. Tedesco S, Souza TP. Territórios da Clínica: Redução de danos e os novos percursos éticos para a clínica das drogas. In: Carvalho SR, Barros ME, Ferigato S, organizadores. Conexões: Saúde coletiva e políticas da subjetividade. São Paulo: Editora Hucitec; 2009. p. 141-156.

Recebido em 13/02/2020

Aprovado em 27/07/2020

Conflito de interesses: inexistente

Suporte financeiro: não houve 